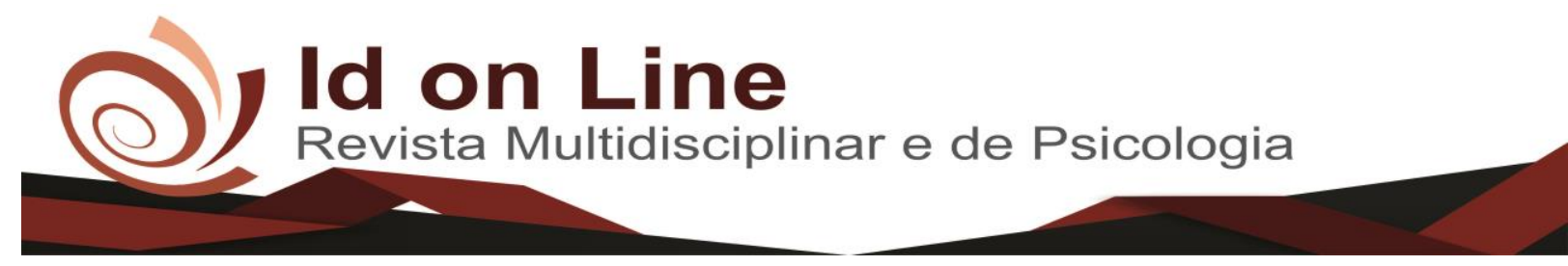

Comment

\title{
A Contribuição do Lúdico na Educação Infantil
}

Naiara Stéfane Soares Santos ${ }^{1}$; Marta Callou Barros Coutinho ${ }^{2}$; Maria do Socorro Cecilio Sobral ${ }^{3}$

Resumo: O presente artigo tem como objetivo discutir e analisar as contribuições do lúdico na prática pedagógica dos professores da educação infantil. A metodologia utilizada foi à revisão bibliográfica, nas bases de dados da CAPES e Scielo dos últimos dez anos, em livros e publicações cientificas. Os resultados do estudo apontaram na direção de que o lúdico é utilizado pelos professores para auxiliar nas práticas pedagógicas e pode ajudar a facilitar o processo de ensino-aprendizagem dos alunos, para alcançar a qualidade desejada em sala de aula. A Contribuição da pesquisa foi como reflexão sobre como as atividades lúdicas ajudam na construção do conhecimento e podem revelar diferentes tipos de sentimentos, levando aos poucos a criança a aceitar a existência do outro e o quanto o educador deve usar e abusar dessa ferramenta na sua prática para melhor conduzir o processo de ensino aprendizagem do estudante.

Palavras-Chave: Criança; Educação Infantil; Lúdico.

\section{The Contribution of the Ludic in Early Childhood Education}

\begin{abstract}
This article aims to discuss and analyze the contributions of the playful or ludic in the pedagogical practice of teachers of early childhood education. The methodology used was the bibliographic review, in the databases of CAPES and Scielo of the last ten years, in books and scientific publications. The results of the study pointed to the fact that play is used by teachers to assist in pedagogical practices and can help facilitate the teachinglearning process of students to achieve the desired quality in the classroom. The contribution of the research was a reflection on how the play activities help in the construction of knowledge and can reveal different types of feelings, gradually lead the child to accept the existence of the other and how much the educator should use and abuse this tool in their practice to better lead the process of teaching student learning.
\end{abstract}

Keywords: Child;Early Childhood Education; Ludic.

\section{Introdução}

O interesse em discutir o lúdico na educação infantil, surge da inquietação pessoal da pesquisadora, enquanto licencianda do curso de Pedagogia, a partir do Estágio Supervisionado em educação infantil e educação especial, vivenciado no $5^{\circ}$ período do curso de Pedagogia e através de observações feitas sobre as práticas pedagógicas dos professores da educação infantil, onde os mesmos utilizavam atividades lúdicas para desenvolver a aprendizagem em

\footnotetext{
${ }^{1}$ Faculdade de Ciências Humanas do Sertão Central (FACHUSC). naiarastefane@ hotmail.com;

${ }^{2}$ Faculdade de Ciências Humanas do Sertão Central (FACHUSC). mcallou@ hotmail.com;

${ }^{3}$ Faculdade de Ciências Humanas do Sertão Central (FACHUSC). socorrosobral@bol.com.br.
} 
sala de aula, surgindo assim, os questionamentos: O lúdico contribui para um melhor desenvolvimento social e cultural das crianças na educação infantil? De que forma o lúdico contribui na aprendizagem das crianças na educação infantil? Os alunos realmente aprendem através do lúdico? Como o professor pode estimular os alunos através de atividades lúdicas?

Nem sempre a educação da criança esteve em destaque, na idade Medieval o sentimento de infância foi esquecido, só apartir do século XVII a igreja juntamente com a escola passam a ter papéis fundamentais nessa educação. No século XVIII a criança passa a ser vista como uma página em branco que poderia ser moldada, conforme a vontade dos demais, apenas somente em meados do século XX por meio de pesquisadores como Piaget e Vygotsky, que apresentam indagações sobre como proceder com formação das crianças e contribuem com o pensamento da importancia que tem a educação para as crianças pequenas.

Piaget (1998) e Vygostsk (1991) contribuem enfatizando que a criança tem capacidade para criar suas próprias hipóteses, sobre o seu ambiente, é um ser atento, criativo, e que se mantém assim constantemente no seu processo desenvolvimento. Ambos destacam que através do contato com o brinquedo a criança passa a distinguir o mundo real a sua volta e a como interagir com os demais, tendo autonomia para buscar formas de se expor sem causar danos para si mesma nesse processo.

Nesse sentido, é através de atividades lúdicas e da relação com brinquedos que a criança passa a construir e moldar uma conexão com o que existe a sua volta, criando ligação com as outras crianças, saindo um pouco da sua zona de conforto e abrindo-se para ter contato e uma troca de experiências com os demais.

Fazendo-se necessário que os educadores adotem uma nova postura sobre a importância de atividades lúdicas no contexto educacional, desligando-se da ideia de que é só na teoria que se aprende, trazendo o lúdico como ferramenta de uso cotidiano, na construção do conhecimento das crianças.

Segundo (Kishimoto, 2010) "a relação das crianças com o brinquedo começa com sua conexão com os adultos, e como essa interação se dá, pois a partir daí ela amplia sua percepção de mundo e se abre para novas descobertas e experiencias”.

Partindo dos conhecimentos já trazidos pelas crianças e estimulando o seu cognitivo ela ampliará seus conhecimentos construindo laços com as pessoas a sua volta, interagindo com o que o ambiente que lhe cerca, ampliando o debate, Kishimoto diz: 
objetos e situações do seu cotidiano e, pela imitação, a linguagem se desenvolve (KISHIMOTO, 2010, p. 5).

A escola tem papel fundamental nessa pratica, pois é responsável por oferecer um ambiente que tenha estrutura para que o aluno possa ter a liberdade de se aprimorar e evoluir com seus conhecimentos e descobertas por meio das brincadeiras, onde será lhe proporcionado, inúmeras possiblidades de escolher como e com o que e de que forma brincar, dentro das possibilidades cada aluno. Ainda para (Kishimoto, 2010, p. 5)

\footnotetext{
As vantagens das brincadeiras de forma lúdica para as crianças são inúmeros, mas para que sejam eficazes é necessário conhecer o público alvo antes de direcionar qualquer atividade para seu desenvolvimento, o que exige do professor ter a relação com seus alunos e fazer uma ponte entre o cuidar e o educar.
}

Tendo em vista que a comunicação entre os dois também se faz essencial nesse processo, é onde a criança passa a ter vontade de construir relações com outras pessoas, faz com que a adaptação a esse novo universo descoberto seja mais tranquila e que o impacto venha a ser menos sentido pela mudança que ocorre em sua vida.

Com o objetivo de analisar as contribuições do lúdico na prática pedagógica de professores da Educação Infantil, essa pesquisa buscou investigar através da revisão bibliográfica, nas bases de dados da CAPES e SCielo dos últimos dez anos, pesquisas que trazem o lúdico como contribuição para o desenvolvimento social e descoberta do mundo. Surgindo assim os objetivos específicos dessa pesquisa: a) compreender como se dá o processo de aprendizagem na educação infantil a partir de atividades lúdicas; b) perceber como se dá a relação lúdica para o desenvolvimento social e cultural das crianças da educação infantil.

O referencial teórico foi dividido em três seções o primeiro apresenta-se: O histórico de formação da criança, educação infantil e seus direitos e, a importância do lúdico na educação infantil.

\section{Histórico de formação da criança}

Na sociedade Medieval a criança não tinha muita afeição da parte dos adultos, quando não necessitasse mais de cuidados básicos de sua mãe eram introduzidas no mundo adulto, e deste não saia mais. Por não haver condições de forma em geral que buscasse ajudar o 
desenvolvimento da criança, a mortalidade infantil era vista como algo bastante corriqueiro, tanto que os adultos achavam normal.

No século XVII a igreja exerce uma importante função junto à escola no papel da educação, porque para a igreja terá que consertar a criança, e livrá-la do pecado de ter sido gerada, onde era considerada pecadora somente por esse fato, a esse respeito afirma Azevedo $(1999$, p. 36) que "a escola dos tempos modernos tornou-se um meio de isolar cada vez mais a criança do mundo dos adultos durante um período de formação e adestrá-la sob o regime disciplinar rigoroso e autoritário”. O que resulta dizer que mesmo com a chegada da escolaridade para as crianças o pensamento ainda era o mesmo, os adultos poderiam molda-las a seu gosto. Já no século XVIII ela passa a ser vista como uma página em branco que necessita de orientação procurando nesse período despertar na criança o sentimento de crescimento pasando a ter reponsabilidades de adultos (AZEVEDO, 1999, p. 35) com base nos estudos de Áries, destaca que:

A criança passou por um período de descoberta em que saiu do seu anonimato e passou para a posição de "adulto em miniatura". Pois a criança não era tão bem vista pelos adultos, costume passado naturalmente na convivência com a família, o segundo é um sentimento que surge através de pessoas que repugnavam a paparicação e que pensavam em moldar a criança para que e fizesse apresentável para a sociedade, num movimento que toma muita força a partir do século XVIII (AZEVEDO, 1999, p. 35)

Neste sentido torna a criança um ser sem pensamentos e vontades próprias, que será moldado de acordo com as normas e regras da sociedade sobre padrões de comportamento e o que se pode ou não fazer.

Apenas por volta do século XX por meio de pesquisadores como Piaget, Freud e Vygotsky, que estão ligados à psicologia do desenvolvimento as teorias psicanalistas e de aprendizagem é que se procuraram métodos para vir a tona a realidade da educação, bem como entender como se dava a aprendizagem, buscando evoluir através das linguagens demonstradas por meio das crianças e por interferências nos primeiros anos de vida da criança.

Para KRAMER (1992):

A educação pré-escolar começou a ser reconhecida e a ser necessária tanto na Europa quanto nos Estados Unidos no período da Depressão de 30. Seu principal objetivo era o de garantir emprego a professores, enfermeiros e alguns outros profissionais, oferecendo um favorecimento de um ambiente saudável e emocionalmente estável para crianças de dois anos de idade. (KRAMER, 1992, p. 26) 
Assim, a criança nesse sistema exerce uma função de massa moldável, o professor é pouco valorizado e a formação humana é deixada de lado e esquecida. É por essa razão e tantas outras que procurar meios de pensar sobre a Educação Infantil é uma forma de buscar respostas para como se deve trabalhar nessa modalidade em toda sua essência.

Percebe-se que dessa forma a definição da história de infância muda, as escolas que recebem as crianças pequenas e têm responsabilidades diferenciadas. Portanto, hoje é preciso ter nítida que o momento atual exige fundamentos a um princípio político de educação infantil em bases sólidas.

\section{Educação Infantil e seus direitos}

O conceito de infância sofreu transformações ao longo da história. Observou-se que, a partir do século XX, é que os estudos mostram a criança como sujeito social de plenos direitos. Essas discussões propiciaram uma visão ampla sobre a relação existente entre o cuidar e educar, e a forma diferenciada em que ela é interpretada pelos pais, creches e pré-escolas.

Com o início da construção do projeto da Lei de Diretrizes e Bases da Educação Nacional (LDB) na Câmara Federal com debates recorrentes pelo processo constituinte dos anos de 1980, a Educação Básica, com mais precisão a Educação Infantil começou a ter mais expressão e respaldo legal do governo federal, com vistas a proporcionar as crianças de 0 a 5 anos atendimento sistemático, organizado, cujo foco volta-se para o cuidar e educar.

Cerisara (1999) oferece uma reflexão que comprova essa mudança de paradigma, transformação esta que muito contribui para que a educação infantil valorize a criança em seu crescimento, em todos os aspectos, tendo em mente que mesmo que o cuidar ainda esteja presente, ele não é tido como condição primordial, mas sim como parte da função do professor desse nível de ensino.

A compreensão de que as instituições de educação infantil têm como função educar e cuidar de forma indissociável e complementar as crianças de 0 a 6 anos é relativamente recente. [...] $\mathrm{O}$ desafio está acima de tudo estreitamente ligado às relações creches-família, que precisam ser reafirmadas de forma significativa o mais depressa possível, para que fique claro o papel que estas duas instituições devem ter no atual contexto histórico, a fim de que as professoras de educação infantil e as famílias - pais e mães das crianças - possam assumir suas responsabilidades com maior clareza dos seus papéis que, mesmo sendo complementares um em relação ao outro, são diferentes e devem continuar sendo (CERISARA, 1999, p. 12). 
Nessa perspectiva, a avaliação que se faz então dos papéis dos pais e dos profissionais de educação infantil, ainda que estes encontrem dificuldades quanto às práticas metodológicas a serem utilizadas, a função e o papel de cada um deve ser complementar e de responsabilidade única, ou seja, entende-se que a creche e a família são instituições que se complementam as duas exercem a função de cuidar e educar,assim quendo ambas assumem seus papéis, resultará em um processo harmônico de formação da criança. Contribuindo com o debate Firmino (2002) nos revela que:

Uma das características que tem marcado as transformações observadas nas creches é a maneira como se dá o contato entre educadoras e mães e/ou famílias das crianças. Até poucos anos atrás, era mais comum a prática de receber e entregar as crianças no portão da instituição. [...] Fomentou-se, assim, a discussão sobre a relação crechefamília e sobre estratégias para abrir as creches à maior participação das famílias. [...] Hoje, é possível encontrar creches abertas, creches mais ou menos abertas, creches fechadas. O processo está ocorrendo, não sem dificuldades (FIRMINO, 2002, p. 24).

Possivelmente, essa barreira existente na perspectiva dos pais ao atendimento de seus filhos ocorre, também, pela falta de informação que possuem e de acesso à própria instituição creche, no intuito de não só verificar, como também participar das ações e atividades pedagógicas propostas pelos centros de educação infantil.

\section{A importância do Lúdico na Educação Infantil}

O Referencial Curricular Nacional para a Educação Infanti (RECNEI) mostra a importância das instituições públicas de Educação Infantil se libertarem, por assim dizer, da ideia de que são escolas para pobres e de que somente o cuidar seja oferecido. Assim, encontram-se as orientações no RCNEI:

Constituir-se em um equipamento só para pobres, principalmente no caso das instituições de educação infantil, que são mantidas pelo poder público ou recebe financiamentos, em muitas situações atuar de forma compensatória para sanar as supostas faltas e carências das crianças e de suas famílias. A tônica do trabalho institucional foi pautada por métodos para rotular a população de baixa renda. Nessa perspectiva, o atendimento era entendido como um favor ofertado a alguns que eram minunciosamente selecionados, concepção educacional era marcada por 
características assistencialistas, sem considerar as questões de cidadania ligadas aos ideais de liberdade e igualdade. Modificar essa concepção de educação assistencialista significa atentar para várias questões que vão muito além dos aspectos legais. Envolve, principalmente assumir as especificidades da educação infantil e rever concepções sobre a infância, as relações entre as classes sociais, as responsabilidades da sociedade e o papel do estado diante das crianças pequenas. (BRASIL, 1998, p. 18, v.1).

É importante destacar que a mudança de paradigma acentuada no documento, pois se antes a educação infantil tinha caráter compensatório, hoje, já se tem nítida a questão dessa etapa da educação ter suas especificidades, as quais devem ser respeitadas.

À medida que a criança começa seu desenvolvimento físico as brincadeiras passam a se tornar mais sociais, os participantes se encontram, numa atividade comum e ao mesmo tempo aprendem a coexistência, contudo lhes possibilita aprender, como lhe dar com respeito mútuo, bem como partilhar brinquedos, dividir tarefas e tudo aquilo que implica uma tarefa coletiva no seu dia-a-dia, Kishimoto diz:

A criança procura o jogo como uma necessidade e não como distração [...]. É pelo jogo que a criança se revela. As suas inclinações boas ou más. A sua vocação, suas habilidades, o seu caráter, tudo que ela traz latente no seu eu em formação, torna-se visível pelo jogo e pelos brinquedos, que ela executa (KISHIMOTO, 1993, p. 106).

Assim, é brincando que a criança começa a se relacionar com as pessoas, que ela descobre o mundo, se desenvolve com o que ela aprendeu, a criança desenvolve com mais saúde, elimina o estresse, aumenta a criatividade e a sensibilidade, estimula o social. Brincar é um dos alimentos mais importantes da infância. Brincar é a atividade que permite que a criança se desenvolva, desde os primeiros anos de vida, todo o potencial que existe nela. Portanto podese dizer que é por meio da brincadeira que faz a criança ser criança, Luckesi diz:

[...] o que a ludicidade traz de novo é o fato de que o ser humano, quando age ludicamente, vivencia uma experiência plena. [...] Enquanto estamos participando verdadeiramente de uma atividade lúdica, não há lugar, na nossa experiência, para qualquer outra coisa além desta atividade. Não há divisão. Estamos inteiros, plenos, flexíveis, alegres, saudáveis. [...] Brincar, jogar, agir ludicamente exige uma entrega total do ser humano, corpo e mente ao mesmo tempo. (LUCKESI, 2000, p. 21). 
Sendo o lúdico de grande importância para as crianças, pois sem distinção de idade ou classe social, estas atividades lúdicas devem constar no contexto político pedagógico da escola. O lúdico compreende os jogos as brincadeiras e os próprios brinquedos, tanto as brincadeiras de antigamente, bem como as atuais, pois são de cunho educativo e auxiliam na aprendizagem dos alunos, assim como no convívio social. É com a interação que as crianças vão desenvolvendo suas criatividades e liberdades.

Mariano (2009) elaborou a dissertação intitulada "Brincadeiras e jogos na educação infantil: o na educação infantil: o lúdico e o processo de constituição de sujeitos numa turma de crianças de 4 e 5 anos". A presente pesquisa afirma que o lúdico é elemento essencial ao desenvolvimento infantil, pois surge marcado pela cultura, sendo mediado pelas relações entre os sujeitos. Objetivou-se analisar quando e como aconteciam atividades lúdicas no dia a dia de uma turma de crianças da educação infantil, além saber em que medida tais ações influenciavam no processo de constituição da professora e de seus alunos. A pesquisa demonstrou que as atividades lúdicas, mesmo sendo consideradas como fatores de aprendizagem, constituem como sujeitos, porém, não foram suficientemente planejadas e/ou acompanhadas pela docente, pois o lúdico acontece em um espaço-tempo limitado, e, muitas vezes, tem sua utilização restrita na prática docente.

Rosa, Kravchychyn, Vieira, (2010) objetivando sintetizar conceitos como cultura lúdica, brincar, brincadeira, bem como demonstrar a importância do brincar para odesenvolvimento humano, fizeram relato de experiência em uma brinquedoteca instalada em uma creche filantrópica. Por meio da análise teórica e do relato de experiência, pode-se concluir que a brinquedoteca é um espaço que valoriza um aspecto fundamental do cotidiano infantil e constitui-se como um espaço privilegiado para a produção de conhecimento sobre a infância e o desenvolvimento infantil. Nesse sentido a pesquisa ajuda a compreender a importância da brinquedoteca para o desenvolvimento da criança e para a construção de valores, desenvolvimento cognitivo, e participação e interação social a partir do brincar.

Santana e Nascimento (2011) como objetivo contribuir para o enriquecimento profissional dos professores que ensinam matemática na perspectiva de um conhecimento mais aprofundado sobre a história do uso do lúdico no processo de ensino e aprendizagem, perceberam que a .importância do lúdico como instrumento metodológico é abordada sob a ótica da utilização dos mesmos na busca de um melhor aprendizado dos alunos, em relação aos conhecimentos matemáticos, com o uso dessas atividades, que favoreçam a exploração do potencial e o desenvolvimento das habilidades que eles proporcionam. Os autores defendem a 
utilização do lúdico em sala de aula como um instrumento metodológico para o ensino da matemática. Os contributos da pesquisa nos adverte que o desenvolvimento de atividades lúdicas na sala de aula , torna-se uma metodologia que facilitara a aprendizagem das crianças.

Vituri (2014) ao investigar sobre a importância do lúdico na educação infantil, objetivando levar os educadores a uma reflexão sobre a importância do brincar, concluindo que é através do brincar que as crianças criam, recriam, aprendem, constroem seus conceitos e valores. Sendo assim, o lúdico permite a criança buscar aprendizagens significativas e ampliando o repertorio de comunicação e o desenvolvimento de aprendizagem.

Santos, F. T. O. (2015) ao investigar o lúdico e o brincar na educação infantil sinaliza que através do lúdico o aluno compreende o que está aprendendo, pois a aprendizagem passa a ser significativa. O educador que ensina conteúdos com jogos em sua sala de aula leva o aluno a ser sujeito de sua aprendizagem; a espontaneidade e a criatividade são constantemente estimuladas. Dessa maneira o lúdico pode ser útil para estimular o desenvolvimento integral das crianças e os professores poderão adotar na praticas com a a utilização de conteúdos curriculares utilizando-se da metodologia com o lúdico .

\section{Metodologia}

Essa pesquisa buscou investigar através da revisão bibliográfica, nas bases de dados da CAPES e SCielo dos últimos dez anos, pesquisas que trazem o lúdico como contribuição para o desenvolvimento social e descoberta do mundo .

\section{Resultados e Discussão}

Com base nos estudos de VYGOTYSKY (1991), observou-se que ele considera o ato da brincadeira extremamente importante para o desenvolvimento da criança. Dessa forma, as crianças se relacionam de várias maneiras com significados e valores, pois, nas brincadeiras elas ressignificam o que vivem e sentem. Portanto, sabe-se que essas atividades dão de certa forma autonomia e um rumo na vida das crianças. Desse modo, as crianças reproduzem várias situações concretas de adultos. Diante disso, o educador deve utilizar as brincadeiras como ferramenta em suas aulas para facilitar o aprendizado. Diante desse quadro, é bom que o 
educador dê espaço para as brincadeiras lúdicas, pois elas auxiliarão no aprendizado das crianças.

De acordo com PIAGET (1998), a natureza de formação educativa da brincadeira é vista como uma atividade formativa, que pressupõe o desenvolvimento integral da criança, seja ela na prática, no intelectual e moral, como também na constituição da individualidade, a formação do caráter e da personalidade de cada um. Enquanto, que na fase dirigida há a presença das atividades lúdicas com o foco voltado para promover a aprendizagem de um determinado conceito, ou seja, além de serem marcados pela intencionalidade do educador.

Para Oliveira, 2006, nos relatos de sua investigação cientifica , considera que o ser humano é "um ser do desejo, mais do que da necessidade", é imprescindível reconhecer que "aprender, pensar e ensinar são atividades investidas de fantasia" dessa forma, a educação não vai além do processo de ensino-aprendizagem, superando apenas os conteúdos escolares, é mais extensa e larga, vai rebater diretamente no ensino e a aprendizagem para a vida; para a formação de cidadãos, provoca ensinar a criança pequena a aprender a viver e conviver.

Landó (2009) dissertou sobre a “Atividade lúdica em práticas de ensino com crianças da educação infantil em creche". Contribuiu com o objetivo dessa pesquisa no aspecto da investigação das práticas de ensino com atividades lúdicas na Educação Infantil em creche, bem como seu papel no desenvolvimento mental e afetivo das crianças. Concluiu que há eficácia do trabalho da professora nos processos mentais das crianças.

Cintra (2014) em sua pesquisa sobre a ludicidade e prática docente na educação da criança: estado da arte conclui que as análises das dissertações do portal da CAPES asseguram que a ludicidade é relevante, que os professores afirmam a importância das atividades lúdicas, porém, observou-se a falta de capacitação para um melhor desenvolvimento do brinquedo e do jogo em algumas instituições de educação infantil.

\section{Considerações Finais}

O presente artigo buscou discutir as contribuições do lúdico na educação infantil, onde o objetivo principal é analisar as suas contribuições para a prática pedagógica de professores na educação infantil e como é utilizada, como ferramenta no processo de ensino-aprendizagem, contribuindo para a construção do conhecimento do aluno. Desse modo o lúdico propõe ser uma peça fundamental no crescimento da criança, e se faz presente na vida escolar, só trará benefícios para ambos envolvidos nesse processo de ensino-aprendizagem. 
Sendo assim os professores desde o planejamento elaboram atividades e métodos para trazer uma qualidade no ensino dirigido aos alunos, e as crianças, assim poderão adquirir mais facilidade para se envolver nas atividades oferecidas. Conclui-se que esse método instiga o aluno a se expressar e demonstrar seus sentimentos, vontades e desejos, portanto, o lúdico utilizado como ferramenta no processo de ensino-aprendizagem traz grandes benefícios tanto em sala de aula como fora dela, onde busca o desenvolvimento completo da criança e o descobrir, com autonomia a viver novas experiências onde ela se tornará protagonista do seu aprendizado.

\section{Referências}

ÁRIES, Flilippe. História social da criança e da família. Rio de Janeiro: Zahar, 1978.

AZEVEDO, Heloísa Helena; SILVA, Lucia Isabel da C. Concepção de Infância e o Significado da Educação infantil. Espaços da escola. Unijuí, n.34, ano 9. Out/Dez, 1999. p.33-40.

BRASIL. Lei de Diretrizes e Bases da Educação Nacional. Lei nº. 9394/96 de 20 de dezembro de 1996. Estabelece as diretrizes e bases da educação nacional. Diário Oficial da União, Brasília, DF. BRASIL. Referencial Nacional para a Educação Infantil. Ministério da Educação e do Desporto, Secretaria de Educação Fundamental. Brasília: MEC/SEF, 1998, vol. 1-3.

BROUGÈRE, G. Jogo e Educação. Porto Alegre: Artes Médicas, 2002.

CAPES 2015. Disponível em: https://acervodigital.ufpr.br/bitstream/handle/1884/42542 Acesso em: 17 set. 2018

CERISARA, Ana Beatriz. Educar e Cuidar: por onde anda a educação infantil? Perspectiva. Florianópolis, n. especial, p. 07-10, jul./dez. 1999.

CINTRA Rosana Carla Gonçalves Gomes. Ludicidade e prática docente na educação da criança: estado da arte. Rev.Eletrônica Pesquiseduca, Santos, v. 06, n. 11, p. 84-96, jan.-jun. 2014. Acesso em: 28 set. 2018

FIRMINO, Sara Alexandra Freita. A vez das famílias: conhecendo as expectativas das famílias sobre a educação e o cuidado de seus filhos de 0 a 3 anos de idade em creche. Relatório Final PIBIC/CNPQ, Universidade Estadual de Santa Catarina, Florianópolis, 2002.

KISHIMOTO, Tizuko Morchida (Org.) Jogo, brinquedo, brincadeira e a educação. $3^{\text {a }}$ Ed. São Paulo: Cortez 1998.

. Jogo, brinquedo, brincadeira e a educação. São Paulo: Cortês, 1999.

. (Org.). O brincar e suas teorias. São Paulo: Pioneira, 2002.

(Org.). Jogo, brinquedo, brincadeira e a educação. $7^{\text {a }}$ Ed. São Paulo: Cortez, 2003 
KRAMER, Sonia. A política do pré-escolar no Brasil: a arte do disfarce. Rio de Janeiro: Achiamé, 1992.

LANDÓ, Sônia Luci Zimmermann. A atividade lúdica em práticas de ensino com crianças da educação infantil em creche. 107 f. Dissertação (Mestrado em Educação)- Pontifícia Universidade Católica de Goiás, Goiás, 2009. Acesso em: 10 set. 2018.

LUCKESI, Cipriano C. Educação, Ludicidade e Prevenção das Neuroses Futuras: uma Proposta Pedagógica a partir da Biossíntese. Ludopedagogia, Salvador, BA: UFBA/FACED/PPGE, v. 1, p. 942, 2000.

MARIANO, Sangellita Miranda Franco. Brincadeiras e jogos na educação infantil: o lúdico e o processo de constituição de sujeitos numa turma de crianças de $\mathbf{4}$ a $\mathbf{5}$ anos. 219 f. Dissertação (Mestrado em Educação)- Universidade Federal de Uberlândia, Uberlândia, MG, 2009. Disponível em: Acesso em: 15 out. 2018.

OLIVEIRA, ML., org. (Im)pertinências da educação: o trabalho educativo em pesquisa [online]. São Paulo: Editora UNESP; São Paulo: Cultura Acadêmica, 2009. 193 p. ISBN 978-85-7983-0228.Available from SciELO Books <http://books.scielo.org>. Acesso em: 9 out. 2018

PIAGET, J. A formação do símbolo: imitação, jogo e sonho, imagem e representação. 3. ed. Rio de Janeiro: Zahar, 1998.

A construção do real na criança. $3^{\mathrm{a}}$ ed. $5^{\mathrm{a}}$ reimpressão. São Paulo: Ática 2003.

ROSA, F. V., KRAVCHYCHYN Helena, VIEIRA Mauro Luis Brinquedoteca: a valorização do lúdico no cotidiano infantilda pré-escola Universidade Federal de Santa Catarina - UFSC - Brasil. Barbarói. Santa Cruz do Sul, n. 33, ago./dez. 2010. Acesso em: 16 out. 2018.

SANTANA, Alexandre, NASCIMENTO P. R. A história do lúdico na educação. Disponível em: https://periodicos.ufsc.br/index.php/revemat/article/view/19400. Acesso em: 22 out. 2018.

SANTOS, Fatima Teresinha Oliveira dos. O lúdico e o brincar na educação infantil,

VELASCO, Calcida Gonsalves, Brincar: o despertar psicomotor, Rio de Janeiro: Sprit, 1996.

VYGOTSKY, L.S. A formação social da mente. São Paulo: Martins Fontes 1991.

Como citar este artigo (Formato ABNT):

SANTOS, Naiara Stéfane Soares; COUTINHO, Marta Callou Barros; SOBRAL, Maria do Socorro Cecílio. A Contribuição do Lúdico na Educação Infantil. Id on Line Rev.Mult. Psic., 2019, vol.13, n.43, p. 139-150. ISSN: 1981-1179.

Recebido: 13/11/2018;

Aceito: 19/11/2018 